\title{
Phage PVP-SE1 as Tool Recognition in Polydiacetylene to Produce Intelligent Packaging
}

Taila V. de Oliveira ${ }^{1,2^{*}}$, Nilda de F. F. Soares ${ }^{1}$, Carla M. Carvalho ${ }^{2,3}$, Pablo Fuciños $^{2}$, Jane S. dos R. Coimbra ${ }^{1}$, Nélio J. de Andrade ${ }^{1}$, Eber A. A. Medeiros ${ }^{1}$ and Paulo P. Freitas ${ }^{2}$

${ }^{1}$ Universidade Federal de Viçosa, Department of Food Technology, Packaging Laboratory, Viçosa, MG, Brazil

${ }^{2}$ International Iberian Nanotechnology Laboratory, Braga, Portugal

${ }^{3}$ Center of Biological Engineering, University of Minho, Braga, Portugal

Correspondence to:

Taila V. de Oliveira

Universidade Federal de Viçosa

Department of Food Technology

Packaging Laboratory, Viçosa, MG, Brazil

E-mail: taveloso@icloud.com

Received: January 30, 2017

Accepted: April 21, 2017

Published: May 31, 2017

Citation: de Oliveira TV, Soares $\mathrm{N}$ de FF, Carvalho CM, Fuciños P, dos R. Coimbra JS et al. 2017. Phage PVP-SE1 as Tool Recognition in Polydiacetylene to Produce Intelligent Packaging. J Food Chem Nanotechnol 3(2): 72-79.

Copyright: (C) 2017 Oliveira et al. This is an Open Access article distributed under the terms of the Creative Commons Attribution 4.0 International License (CC-BY) (http://creativecommons. org/licenses/by/4.0/) which permits commercial use, including reproduction, adaptation, and distribution of the article provided the original author and source are credited.

Published by United Scientific Group

\section{Abstract}

Polydiacetylene (PDA) compound has unique chromatic properties when embedded in methylcellulose base. Therefore, this could be used as intelligent packaging. PDA exhibits blue-to-red color transition under certain stimuli, which was caused by alterations in PDA conjugation length backbone. For a specific color modification, bio-recognition tools were covalently linked with PDA. In this work, a broad-spectrum virulent phage (PVP-SE1) was used as a biorecognition element to detect Salmonella cells due to PDA color change. A series of experiments were performed to monitor colorimetric response. Consequently, chromatic immunoassay could be significant in increasing potential applications of PDA intelligent packaging.

\section{Keywords}

Polydiacetylene PDA, Salmonella, Phage PVP-SE1, Film, Intelligent packaging, Methyl cellulose

\section{Introduction}

In recent years, new technologies are demanded to satisfy the necessity of quick and simple methods in comparison to the standard methods to improve bacteria detection in complex system such as food [1]. Biosensors have been intensively studied to fulfil this necessity and could be defined as analytical tools that identify and quantify desired target substances from unknown samples [2]. One compound that has been used as a biosensor is the polydiacetylene (PDA), a polymer which has capability to cause modifications in intramolecular conformation and intermolecular packaging, resulting in changes in absorption, fluorescence, and conductive properties of this polymer [2-6].

Over the last decades, PDA-based biosensors research has been focused on mimicking cell membrane, but these studies presented lack of selectivity to target pathogens [7]. To solve this lack of sensitivity antibodies are incorporated in free carboxyl groups of PDA, which are responsible for the remarkable ability to detect, locate, recognize, and bind with a target antigen. Antibodies are glycoprotein molecules originating from B cells, circulating through the blood and lymph. Each antibody molecule has a unique structure that allows their connection to a specific antigen correspondent. They all have the same general structure and are also called immunoglobulin [8]. Previous work showed that the monoclonal antibody sc-58018 was specific to Salmonella and Oliveira et al. [9] study presented the best condition to use this sensor in food area.

On the other hand, there is a trend to use bacteriophages as a biorecognition 
tool. Bacteriophage is used as sensor receptors to discriminate between viable but non-culturable cells (VBNC). Phages are viruses that infect only bacteria not humans. They considered potential biorecognition elements as well as biodetection tools. That is due to their high specificity to bacteria, robustness, great stability, even under adverse environmental conditions, and extended shelf life. These characteristics, combined with their innocuous nature and low production costs, led the Food and Drug Administration (FDA) to approve some phagebased diagnostic protocols for pathogen detection. Phage PVP-SE1 was indicated to recognize Salmonella spp. from Enterobacteriaceae family. Enterobacteriaceae family contains a large number of genre that are biochemically and genetically related to one another as Escherichia, Shigella, Salmonella, Enterobacter, Proteus, Yersinia [10]. Because that, phage PVPSE1 isolated from Germany waste water, can show a lack of selectivity for this different genres of Enterobacteriaceae family [11]. Despite of it, the lytic phage PVP-SE1 was explored as an alternative of biorecognition element for bacteria detection due to the viability assessment and because that could be used as a receptor for PDA sensor.

Several studies have demonstrated the incorporation of PDA in solid support amplifying the versatility and practicality of the sensor. One of the most straightforward methods to produce PDA film is by mixing the PDA sensor with polymer matrices and then casting the mixture in Petri dish or spin casting producing a composite film [12]. Kim et al. [13] reported the production of nanocomposite films by the PDA embedded in poly (vinyl alcohol). However, other types of polymers could be used as matrix to manufacture nanocomposites with differentiated characteristics.

New technologies of producing packaging with intelligent functions have been developed to fulfil the requirement of conscious consumers for freshness and safety food products [14-16]. Therefore, this research aims to develop a smart packaging with polydiacetylene system to detect Salmonella in foods using the approach of color changes.

\section{Material and Methods}

\section{Materials}

All chemicals of high analytical grade were used without further purification. The diacetylene (DA) monomers (10,12-pentacosadiynoic acid), N-hydroxysuccinimide (NHS), ethyl(dimethylaminopropyl) carbodiimide (EDC), cholesterol (CHO), HPLC-grade chloroform, HPLCgrade dimethylsulfoxide (DMSO) and methyl cellulose were purchased from Sigma- Aldrich (St. Louis, USA). Sphingomyelin (SPH) from chicken egg yolks was obtained from Fluka/Sigma-Aldrich (St. Louis, Missouri, EUA). Lyophilized Bovine Serum (Bio-Rad, CA, USA). Milli-Q (>18 M $\Omega$ ) water was used as solvent. Salmonella Enteritidis S1400, Escherichia coli CECT434, E. coli n5, E. coli $\mathrm{n}^{\circ}$, Yersinia kristensenii PL115185, (SA)5430, Yersinia enterocolitica PL129178,(SA)5429, Enterobacter sakazakii ATCC 51329, Klebsiella pneumoniae ATCC11296, Shigella sonnei ATCC25931, Shigella dysenteriae ATCC11835, Enterobacter aerogenes CECT 684, Shigella boydii ATCC9207, Salmonella typhimurium LT2, S. Enteritidis SGSC 2476, Salmonella gallinarum SGSC 2478, S. Enteritidis NCTC13349, S. Enteritidis SGSC 2474, Salmonella bongori SGSC 3100, Salmonella typhi SGSC3036, Salmonella typhimurium NCTC12416, S. Enteritidis SGSC 2476, Salmonella Montevideo SGSC 2488, Salmonella Newport SGSC2493, Salmonella Dublin SGSC 2470, Salmonella Indiana SGSC 2482, Salmonella Stanley SGSC 2517 belong to the University of Bristol (UK) private collection [17], E. coli ATCC 10536 and Staphylococcus aureus ATCC 25923 were kindly provided by the University of Minho (Braga, Portugal) as indicated in Table 1 . The stock culture was maintained at $-80{ }^{\circ} \mathrm{C}$ in luria bertani medium (LB) (Liofilchem Bacteriology, Italy) with $10 \%(\mathrm{v} / \mathrm{v})$ of glycerol. Stock culture was activated twice in $\mathrm{LB}$ and was incubated at $(37 \pm 2)^{\circ} \mathrm{C}$ for $24 \mathrm{~h}$. Phage PVPSE1 was isolated from a Regensburg (Germany) wastewater plant in the context of a European Project (Phagevet-P). $S$. Enteritidis strains S1400 were used as host.

\begin{tabular}{|c|c|}
\hline Bacteria Strain & Code \\
\hline Escherichia coli CECT434 & $\mathrm{E}$ \\
\hline Yersinia kristensenii PL115185, (SA)5430 & $\mathrm{Y}$ \\
\hline Yersinia enterocolitica PL129178, (SA)5429 & $\mathrm{Y}$ \\
\hline Escherichia coli $\mathrm{n}^{\circ} 5$ & $\mathrm{E}$ \\
\hline Escherichia coli no9 & $\mathrm{E}$ \\
\hline Enterobacter sakazakii ATCC 51329 & $\mathrm{E}$ \\
\hline Klebsiella pneumoniae ATCC11296 & $\mathrm{K}$ \\
\hline Shigella sonnei ATCC25931 & $\mathrm{SH}$ \\
\hline Shigella dysenteriae ATCC11835 & $\mathrm{SH}$ \\
\hline Enterobacter aerogenes CECT 684 & $\mathrm{E}$ \\
\hline Shigella boydii ATCC9207 & $\mathrm{SH}$ \\
\hline Salmonella Typhimurium LT2 & $\mathrm{S}$ \\
\hline Salmonella Enteritidis SGSC 2476 & $\mathrm{~S}$ \\
\hline Salmonella Gallinarum SGSC 2478 & $\mathrm{~S}$ \\
\hline Salmonella Enteritidis NCTC13349 & $\mathrm{S}$ \\
\hline Salmonella Enteritidis SGSC 2474 & $\mathrm{~S}$ \\
\hline Salmonella Bongori SGSC 3100 & $\mathrm{~S}$ \\
\hline Salmonella Typhi SGSC3036 & $\mathrm{S}$ \\
\hline Salmonella Typhimurium NCTC12416 & $\mathrm{S}$ \\
\hline Salmonella Enteritidis SGSC 2476 & $\mathrm{~S}$ \\
\hline Salmonella Montevideo SGSC 2488 & $\mathrm{~S}$ \\
\hline Salmonella Newport SGSC2493 & $\mathrm{S}$ \\
\hline Salmonella Dublin SGSC 2470 & $\mathrm{~S}$ \\
\hline Salmonella Indiana SGSC 2482 & $\mathrm{~S}$ \\
\hline Salmonella Stanley SGSC 2517 & $\mathrm{~S}$ \\
\hline
\end{tabular}

\section{Vesicle preparation}

Polydiacetylene vesicles were prepared according to a modified method from Pires et al. [1]. Solution of $1 \mathrm{mM}$ poly (pentacosadiynoic acid), PCDA, was dissolved in $2 \mathrm{~mL}$ of DMSO and heated at $(80+5){ }^{\circ} \mathrm{C}$ for $(15+0.5)$ 
min. In a separate flask, SPH/CHO $(1 \mathrm{mM})$ was dissolved in chloroform and the solvent was removed under nitrogen flow. After cooling at $(25+2){ }^{\circ} \mathrm{C}$ both solutions were mixed and brought to a final volume of $10 \mathrm{~mL}$ with Milli-Qwater. Vesicle suspensions were sonicated for $(5+0.5)$ min. using a probe sonicator (Branson Digital Sonifier, models $250 \& 450$ ) at $400 \mathrm{~W}$ of power and then filtered through a $0.25 \mu \mathrm{m}$ PVDF filter. The filtrate was cooled to $(4+0.5)^{\circ} \mathrm{C}$ overnight. The next step was the receptor incorporation.

\section{Receptor incorporation}

The receptor was incorporated according to a modified method from Dong et al. [18] and Oliveira et al. [19] as illustrated in Figure 1. The PCDA carboxylic acid was activated by a reaction with NHS and EDC at a molar ratio of 1:1.8:1.8, respectively, during $(60+5)$ min, under constant agitation. PVPSE1 phage $(1: 3000 \mathrm{v} / \mathrm{v})$ was added to the PDA solution and allowed to react for $(5+0.5) \mathrm{h}$ at $(4+0.2){ }^{\circ} \mathrm{C}$ on a shaker (MS1 model, Germany). The occurrence of nonspecific absorption was evaluated after adding, $150 \mu \mathrm{g} / \mathrm{mL}$ of BSA solution in half of the samples of PDA vesicles incorporated with PVPSE1. The other half of the samples was maintained without BSA solution therefore assumed as the control samples. The vesicles were cooled overnight to $(4+0.2){ }^{\circ} \mathrm{C}$. The vesicle polymerization was carried out using the $254 \mathrm{~nm}$ UV light exposure (Prodicil, Brazil, $110 \mathrm{~V}$ ) for $10 \mathrm{~min}$. to convert PCDA monomers in PDA polymer, which were stored at refrigerator temperature. The PDA vesicles with and without BSA solution were submitted to studies of specificity and stability using $S$. Enteritidis, $S$. aureus, and E. coli as presented in the next topic.

Specificity study of the PDA vesicle incorporated with PVP-SE1

The specificity of the sensor was analyzed by adding separately, in the PDA sensor, $50 \mu \mathrm{L}$ of $S$. aureus ATCC $25923(\mathrm{OD} 600=0.60+0.05)$ and $50 \mu \mathrm{L}$ of $E$. coli ATCC $10536(\mathrm{OD} 600=0.60+0.05)$ as gram-positive and gramnegative controls, respectively. LB medium $(50 \mu \mathrm{L})$ was added in the PDA sensor as control to ensure that color change did not occur due to the medium influence. $S$. Enteritidis strain S1400 (OD600 $=0.3+0.05 ; 50 \mu \mathrm{L})$ was incorporated in the PDA sensor to verify the color transition over time with and without BSA addition. The spectra were obtained using a Thermo Scientific Nano Drop 2000 C Spectrophotometer at room temperature $(25+2)^{\circ} \mathrm{C}$ in the range of (400 to 700) $\mathrm{nm}$. Charych et al. [20] proposed a semi-quantitative measurement to evaluate the colorimetric transition, which was defined as colorimetric response $(\mathrm{CR})$ :

$\mathrm{CR}=\{[($ Ablue $/($ Ablue + Ared $)) \mathrm{b}-($ Ablue $) /($ Ablue + Ared $)) \mathrm{a}] /[($ Ablue/(Ablue + Ared $)) \mathrm{b}]\} \times 100$------(1)

Where "A" is the absorbance for the blue $(\sim 650 \mathrm{~nm})$ or red $(\sim 540 \mathrm{~nm})$ component obtained by UV-Vis spectroscopy. The terms "blue" and "red" refer to the color showed by the material, and the indexes/subscripts " $b$ " and "a" stand for the absorbance readings after bacteria addition at zero time of incubation and at 3 days of bacteria incubation, respectively.

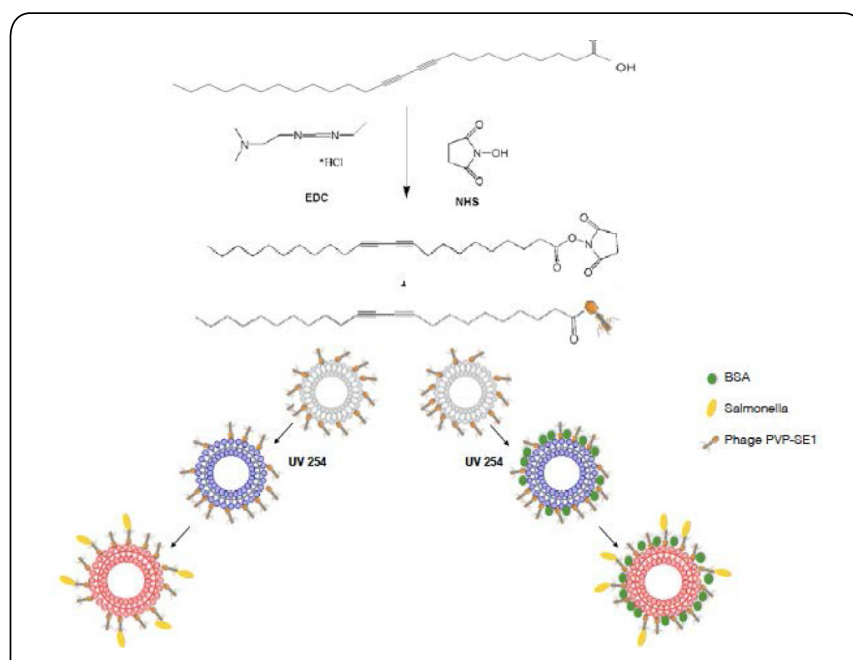

Figure 1: Schematic illustration of the chromatic immunoassay based on polydiacetylene vesicle. The carboxylic acid units of PCDA were converted into the corresponding succinimidyl active ester by treatment with excess N-hydroxysuccinimide (NHS) and ethylcarbodiimid (EDC) in aqueous solution. The activated vesicles which were covalently attached with phage PVP-SE1 conjugates were photopolymerized under UV radiation became conjugated polymer (PDA) and assumed a blue color solution. Part of PDA's vesicles incorporated with phage PVP-SE1 was blocked with BSA (Bovine Serum Albumine). In S.Enteritidis presence, the color of the PDA's system changed from blue to red.

Other types of pathogenic bacteria were analyzed (OD600 $=0.6+0.05)$ to verify the sensor specificity to them at the time (optimized time) in which most PDA vesicles incorporated with receptors showed the highest $\mathrm{CR}$, at 3 days of incubation time at $(37+2){ }^{\circ} \mathrm{C}$. The optimized time was used to confirm that no target bacteria strains change the color of PDA vesicles incorporated with receptor from blue to red. The used bacteria were as described in materials step.

Detection limit of PDA vesicles incorporated with phage PVP-SE1

The $S$. Enteritidis $\mathrm{S} 1400$ was activated in LB broth at $(37+$ 2) ${ }^{\circ} \mathrm{C}$ during $24 \mathrm{~h}$ to determine the detection limit of the PDA sensor. The optical density was corrected for OD600 $=0.6+$ 0.05 assuming the bacteria counting was around $10^{8} \mathrm{CFU} \cdot \mathrm{mL}^{-1}$, and diluted solutions were made using $0.1 \mathrm{~mL}$ from mother solution in $9.9 \mathrm{~mL}$ of $\mathrm{LB}$ broth to generate solutions with concentrations of 10 CFU.mL ${ }^{-1}, 10^{2}$ CFU.mL ${ }^{-1}, 10^{4}$ CFU. $\mathrm{mL}^{-1}$ and $10^{6} \mathrm{CFU} \cdot \mathrm{mL}^{-1}$. The color changes were measured by Thermo Scientific Nano Drop 2000c Spectrophotometer and the colorimetric response $(\mathrm{CR})$ was calculated according to the equation 1 as described in previous section.

\section{Bacterial strains count bounded with receptor PVP-SE1}

The amount of Salmonella bound to the receptor was determined through the difference between the total bacteria added in PDA vesicles at time zero and the total bacteria grown in PDA vesicles after $24 \mathrm{~h}$ of incubation at $(37+2){ }^{\circ} \mathrm{C}$. $S$. Enteritidis S1400 was previously activated in LB broth at $(37+2){ }^{\circ} \mathrm{C}$ during $24 \mathrm{~h}$. The optical density was corrected for $\mathrm{OD} 600=0.6+0.05$ assuming the bacteria counting was around 108 CFU.mL ${ }^{-1}$. An aliquot of $10 \mathrm{~mL}$ of bacteria suspension was centrifuged $(6000 \mathrm{~g})$ during $10 \mathrm{~min}$ at $(4.0$ 
+ 2) ${ }^{\circ} \mathrm{C}$, washed with $0.1 \mathrm{M}$ phosphate buffer (twice), and the content of the centrifuged was completed with $10 \mathrm{~mL}$ of phosphate buffer. Thus, only strain bacteria were suspended in phosphate buffer assuming the bacteria counting was around 108 CFU.mL ${ }^{-1}$. Next, $200 \mu \mathrm{L}$ of PDA vesicle were added to $50 \mu \mathrm{L}$ of that solution. Next, two types of solutions were formed; the first one with phage PVP-SE1, and the other was not incorporated with any receptor (control). The PDA vesicles added with $S$. Enteritidis strain bacteria suspended in buffer phosphate went through successive dilutions $(0.1 \mathrm{~mL}$ from mother solution in $9.9 \mathrm{~mL}$ of buffer phosphate) to obtain solutions with concentrations between $102 \mathrm{CFU}_{\mathrm{mL}}^{-1}$ and 104 CFU.mL ${ }^{-1}$. Aliquots of $0.1 \mathrm{~mL}$ of each diluted solution were plated on LB agar and incubated at $(37+2){ }^{\circ} \mathrm{C}$ during $24 \mathrm{~h}$. Bacteria were counted and the difference between the total bacteria and the free bacteria was assumed as the number of bacteria bounded with the receptor.

\section{PDA embedded in methyl cellulose films}

Embedment of PDA supramolecules in methyl cellulose films was carried out by a mixing drying process as suggested by Kim et al. [13]. PDA vesicle incorporated with phage PVP-SE1 without photopolymerization was mixed with the methyl cellulose solution ( $1 \mathrm{wt} \%, 20 \mathrm{~mL}$ water) using constant stirring. The resultant mixture was cast into a Petri dish $(90$ $\mathrm{cm}$ diameter) and dried at $(37+2){ }^{\circ} \mathrm{C}$ during one day. The dried films were peeled from the dish and the thickness was measured using a manual thickness gauge. The diacetylene embedded film was irradiated at $254 \mathrm{~nm}$ UV light (Prodicil, Brazil, $110 \mathrm{~V}$ ) for $10 \mathrm{~min}$. each side, acquiring blue color after PDA polymerization. After that, the PDA film was stored at $(4+0.2){ }^{\circ} \mathrm{C}$ inside a glass plate until usage.

\section{Bacteria preparation for the study of PDA films}

Bacteria (S. Enteritidis S1400, E. coli ATCC 10536, and $S$. aureus ATCC 25923) were cultured in Luria broth at (37.0 $+2.0)^{\circ} \mathrm{C}$ overnight. Then, $0.1 \mathrm{~mL}$ of each bacteria were plated on Luria broth agar plate and the plates were incubated at $(37.0+2.0)^{\circ} \mathrm{C}$ overnight followed by the specificity study [21]

\section{Specificity study of PDA intelligent packaging}

Methyl cellulose films embedded with PDA incorporated with PVP-SE1 were cut in $(1 \times 1) \mathrm{cm}^{2}$, placed on LB agar surface containing spreading bacteria ( $S$. Enteritidis S1400, $E$. coli ATCC 10536, and $S$. aureus ATCC 25923), and incubated at $(37.0+2.0){ }^{\circ} \mathrm{C}$ during $24 \mathrm{~h}$. Color images of the indicators were taken using a Microscope Nikon (Type 104, Model C-Pol, China).

\section{Environmental Scanning Electron Microscopy images of PDA films embedded in methyl cellulose}

Environmental Scanning Electron Microscopy (ESEM) was used in scanning electron mode to obtain images of the PDA embedded in methyl cellulose, with phage PVP-SE1 incorporation and without receptor (control), using Quanta 650 FEG (FEI) Microscope. PDA films were put directly onto a carbon-coated copper mess and characterized using low vacuum and low electron voltage behavior [22].

\section{Results}

The specificity study was carried out to test if the phage PVP-SE1 incorporated in PDA vesicles ensure that PDA color transition occur only in the Salmonella strains presence during the 30 days of incubation at $37^{\circ} \mathrm{C}$. The stability of the color change over the time was also evaluated in those conditions. E. coli ATCC 10536 and S. aureus ATCC 25923 were used as gram-negative and gram-positive control, respectively, to ensure that the color change did not occur due to the presence of other pathogens. According to Oliveira et al. [23] and Pires et al. [1], E. coli and $S$. aureus may change color in less than $48 \mathrm{~h}$ when using Lysine and $\mathrm{N}$-[(2-teradecanamide)-ethyl]ribonamide as receptors or without receptor incorporation. This means that phage PVP-SE1 incorporation cause specific interaction between Salmonella serovar in PDA vesicles.

In addition to receptor specificity assessment, an additional study was performed to understand the role of block step with BSA compound to avoid unspecific binding in carboxyl groups, which could hinder PDA vesicle color change. When PDA-PVP-SE1 sensor was blocked with BSA, the CR was improved (CR maximum around 40\%) overtime, differently from unblocked PDA-PVP-SE1, which have denoted CR reduction (CR around 20\%) due to aggregation in due course. Moreover, a color change has happened when none target bacteria were added. Therefore, the free carboxyl groups blocking step was important to certify PDA sensor specificity. This was essential to avoid other alteration causes that could be resulted from the interaction between free carboxyl groups and unmarked bacteria. Consequently, an unspecific color change have occurred. Additionally, there was other role played by that step to maintain stability due to the prevention of aggregated formation between PDA vesicles over the time. Thus, the stage intending to block free carboxyl groups with BSA was incorporated in every experimental procedures hereafter.

PDA vesicle color change when incorporated with phage PVP-SE1 after Salmonella addition could be visualized by unaided eyes as shown in Figure 2. The color has changed twice with PVP-SE1 receptor incorporation into PDA vesicle: 1) the blue color have altered to purple with CR ranging from (8.0 to $12.0 \%$ ) 2) the purple color was modified to pink (or red) as CR ranged from (15.0 to $17.0 \%)$. The $\mathrm{CR}$ range in each stage is a function of color degree saturation. PDA vesicle color change was more noticeable by unaided eye as $\mathrm{CR}$ increased over time. For better understanding, CR 10\% (purple color) was considered

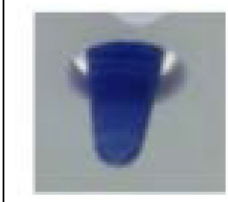

(a)

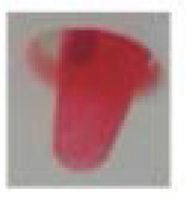

(b)

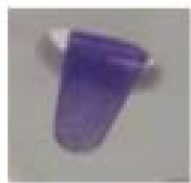

(c)

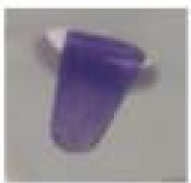

(d)
Figure 2: Color transition for PDA vesicles incorporated with phage PVP-SE1. (a) Blue color: without bacteria; (b) pink (or red) color: with S Enteritidis S1400; (c) purple color: with E. coli ATCC 10536; (d) purple color: with S. aureus ATCC 25923. 
the initial stage and CR 15\% (red color) the second step.

After S. Enteritidis S1400 (OD600 $0.6+0.1)$ incorporation, the color change to purple was perceptible by bare eye since the first day. However, the CR was able to indicate a difference between systems colors without and with targeted bacteria ( $S$. Enteritidis S1400, E. coli ATCC 10536 and $S$. aureus ATCC 25923) in PDA vesicles incorporated with phage PVP-SE1 only at 15 incubation days at $(37+2)$ ${ }^{\circ} \mathrm{C}$. This could be demonstrated according to the statistical test ANOVA, at 0.05 level. PDA vesicles CR has improved sensitiveness over time. The red color in PDA vesicles has took about 3 incubation days at $35^{\circ} \mathrm{C}$ to appear.

Intending to protect $\mathrm{PDA}$ sensor specificity, other bacteria were tested with 3 incubation days at $(37+2){ }^{\circ} \mathrm{C}$; and to verify its sensitivity, several Salmonella serovar were analyzed as well. Color changes outcomes, quantified by Thermo Scientific Nano Drop 2000 C Spectrophotometer were used to calculate colorimetric response (CR), according to equation 1 described under the section "specificity study of the PDA vesicle" utilizing bacteria strain listed in Table 1 . These results were expressed in Figure 3.

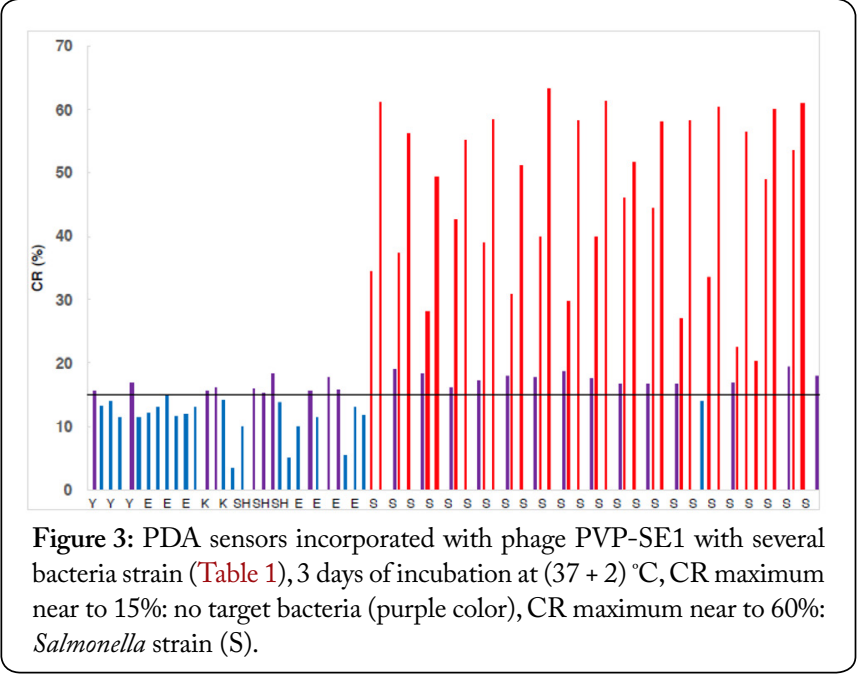

Phage PVP-SE1 showed specificity for Salmonella strain with slight differences at each behavior. The phage PVP$\mathrm{SE} 1$ changed the color from blue to purple in the presence of pathogens, but only for Salmonella strain the PDA sensor changed the color from blue to pink (or red). In Figure 3, for the Salmonella strain, the CR was very high with the maximum value around $60 \%$ and the minimum near to $\mathrm{CR}$ $15 \%$. If no target pathogenic bacteria were used the CR maximum was around $15 \%$ and the minimum was $0 \%$. The difference among the $\mathrm{CR}$ values was improved, what means it was easier to differentiate the color for Salmonella strain then pathogen strain, over the incubation time. In addition to that, the receptor phage PVP-SE1 was capable to detect almost all the types of Salmonella serovars, showing to be a versatile receptor. Therefore, phage PVP-SE1 can be used to point out bad microbiological conditions of stored food once spoilage bacteria present in foods could present an intermediary color, the purple color, that indicate unsatisfactory sanitary food condition. On the other hand, the change color from blue to red in Salmonella presence indicate unsafe condition of the food because the presence of the pathogen render the food a risk for health [24].

In contrast, PDA vesicles without a receptor were able to modify the color from blue to red regardless bacteria type incorporated into PDA system. That color alteration emphasizes receptor incorporation importance for a specific detection. Whether the purpose is only sensitivity, the PDA vesicles without a receptor could represent an appropriate sensor to indicate bacteria presence in food. Nonetheless, this work has focused on Salmonella spp. detection as this microorganism represents the major cause of food poisoning worldwide. The majority of outbreaks are due to subspecies enterica serovar Enteritidis contamination of eggs, chicken and swine. Contaminated foods, usually present none signs of microbial alteration [25]. PVP-SE1 phage incorporation was an important step due to its capability to indicate unsafe conditions by the Salmonella spp. presence, exhibiting the red color sensor. Moreover, deteriorating bacteria have shown purple color sensor, which signifies bacteria contamination in food. In other words, when PVP-SE1 phage was assimilated in PDA sensor, this could send three messages for consumers: red indicating Salmonella presence, purple denoting other pathogenic bacteria genres presence, and blue designating food in suitable conditions. Scanning Electronic Microscope picture (Figure 4) showed the interaction bettween $S$. Enteritidis, as a mass shape, and phage PVP-SE1 incorporated in PDA's vesicles, which caused the color change.

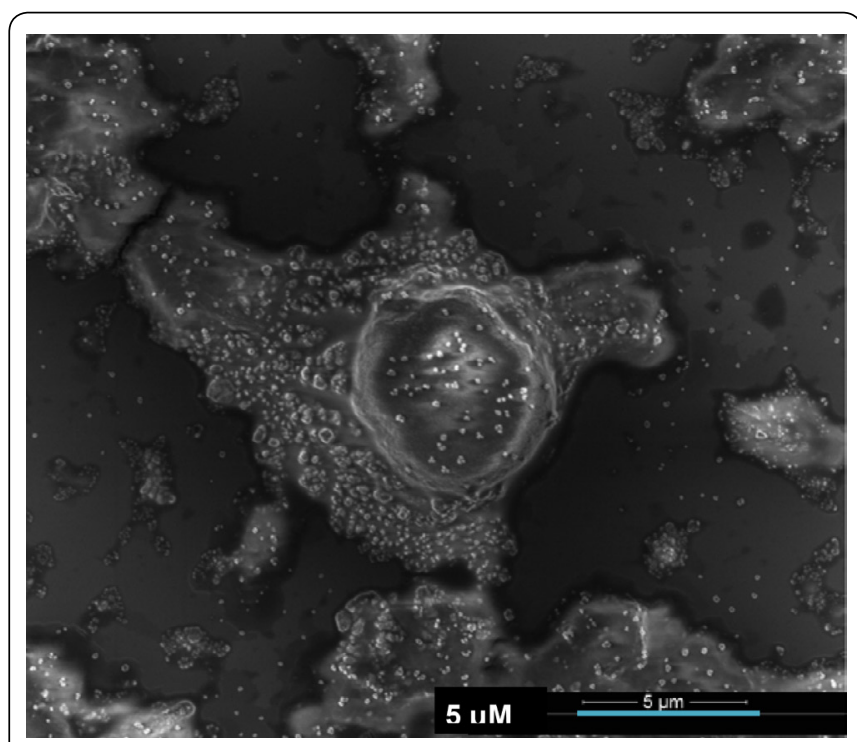

Figure 4: SEM pictures of PDA vesicles incorporated with phage PVPSE1 in S.Enteritidis presence.

Regarding the detection limit, the number of bacteria bonded in PVP-SE1 was around 101 CFU.mL ${ }^{-1}$ of $S$. Enteritidis S1400 when 108 CFU.mL ${ }^{-1}$ were added. The PDA vesicle incorporated with PVP-SE1 showed the purple color when Salmonella was between $10^{\circ}$ to 106 CFU.mL ${ }^{-1}$ with CR values around $15 \%$ and the red color manifested just after the addition of 108 CFU.mL ${ }^{-1}$ of $S$. Enteritidis S1400 with CR under $30 \%$. 
The next step of our investigation was the immobilization of the PDA sensor in a solid support. Several studies with PDA films were reported in the literature. Scindia et al. [16] developed glass-supported films of lipids and polydiacetylene for visual detection and colorimetric fingerprinting of bacteria. Meir et al. [26] constructed agarose-embedded chromatic films to obtain color changes and fluorescence transformations in response to bacterial growth. Ma et al. [27] developed a film using polydiacetylene with mannose assembled by LangmuirBlodgett technology to detect $E$. coli. Nevertheless, none of these studies the film could be used as intelligent packaging due to the complexity of the techniques and the features of the films. An exception could be the Kim et al. [13] study that reported the production of nanocomposite films by the PDA embedded in poly (vinyl alcohol). However, this polymer base difficult the color change even upon temperature expose.

Therefore, in this research, PDA sensors incorporated with PVP-SE1 was embedded in methyl cellulose to produce intelligent packaging for colorimetric detection of Salmonella in food. The specificity of the film for S. Enteritidis S1400 comparing with $S$. aureus ATCC 25923, as gram-positive control, and E. coli ATCC 10536, as gram-negative control was done. Images (Microscope Nikon Type 104, Model C-Pol, China) of the PDA films after $24 \mathrm{~h}$ at $(37+2){ }^{\circ} \mathrm{C}$ in contact with the bacteria grown in LB medium were taken. The images were treated in the Math Lab program as shown in Figure 5 for PDA incorporated with PVP-SE1 phage embedded in methyl cellulose.

The E. coli ATCC 10536 and S. aureus ATCC 25923 were able to modify the initial color of the PDA film, from blue to purple, but only $S$. Enteritidis S1400 changed the color from blue to red. The phage PVP-SE1 receptor was important to improve the difference of the color appearance between target bacteria (Salmonella) and the others (E. coli, S. aureus). The same behavior could be observed in PDA vesicles incorporated with phage PVP-SE1 in the presence of bacteria. However, the color of the films were changed after one day whereas the color of the vesicles took three days to change, at the same temperature condition $(37+2){ }^{\circ} \mathrm{C}$.
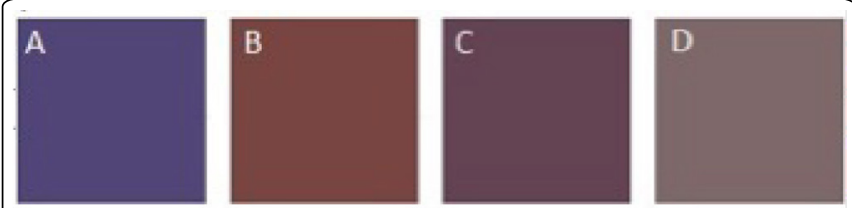

Figure 5: Images of the PDA incorporated with phage PVP-SE1 embedded in methyl cellulose after $24 \mathrm{~h}$ of direct contact: (A) without bacteria; (B) with $S$. Enteritidis S1400; (C) with S. aureus ATCC 25923; (D) with $E$. coli ATCC 10536 addition.

Color transition measurement was performed assisted by Mathematic program to calculate the difference between primary color component of the PDA film with and without bacteria, as shown in Figure 4. RGB (Red, Green, and Blue) color space consists of a three-dimensional rectangular coordinate system with R, G, and B axes [28]. PDA films with and without $S$. Enteritidis S1400 have shown the sharpest color differences when PVP-SE1 was incorporated into films embedded in methylcellulose. This indicates that primary color components of PDA film incorporated with PVP-SE1, in the presence of $S$. Enteritidis S1400, were more distinctive from those primary color constituents of PDA films incorporated with PVP-SE1 without bacteria, mainly for red component. When other bacteria (E. coli ATCC 10536 and $S$. aureus ATCC 25923) were utilized, color difference from film without bacteria was inferior (Figure 6).

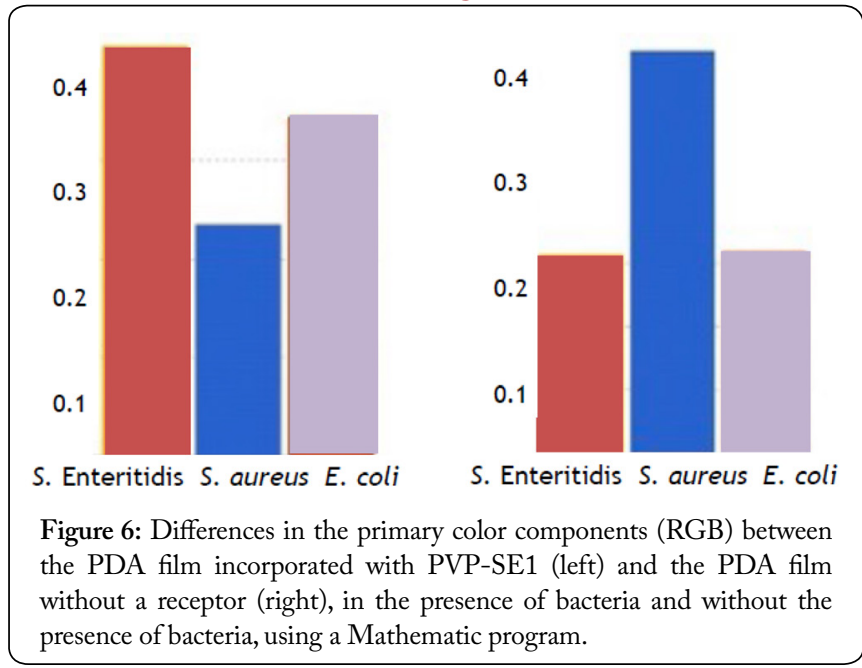

According to the outcomes, color transition in PDA system resulted from $S$. Enteritidis $\mathrm{S} 1400$ needed a specific receptor presence. PVP-SE1 incorporation into PDA film embedded in methylcellulose did not prevent color change by other pathogenic bacteria. Nevertheless, Salmonella color transition (from blue to red) from the E. coli ATCC 10536 and $S$. aureus ATCC 25923 color transition could be differentiated (from blue to purple). PDA incorporated with PVP-SE1 and embedded in methylcellulose can aware consumers about food quality, since purple color points out $E$. coli and $S$. aureus presence in the food whereas a red color is an indicative $S$. Enteritidis occurrence.

Characterization of the PDA vesicles using Atomic Force Microscopy (AFM) and Scanning Electronic Microscopy (SEM) were carried out after colorimetric evaluation aiming to discuss PDA vesicles arrangement in methyl cellulose and their relation with the colorimetric transition. PDA vesicles embedded in methyl cellulose without the receptor incorporation showed lower roughness than the vesicles with phage PVP-SE1. This roughness data together with the SEM pictures (Figure 7) shown the preservation of the sphere shape of the PDA vesicle in the presence of the receptor. Kim et al. [13] and Pevzner et al. [29] also found a sphere shape for PDA vesicles and PDA aggregates. The authors showed that the surface depend upon the type of phospholipids and the molecular ratio between the phospholipids and diacetylene, indicating the formation of interdependent domains among lipids and methyl cellulose polymer within the vesicles. Therefore, the incorporation of the PVP-SE1 receptor in PDA vesicles embedded in methyl cellulose can improve their stability and can preserve their sphere shape contributing to preserve their specificity regarding the color change, mainly in the presence of Salmonella. On the other hand, PDA vesicles without receptor incorporation lost their shape when mixed with methyl cellulose polymer. 
PDA incorporated with phage PVP-SE1 embedded in methyl cellulose produces a blue plastic film with potential to be used as advanced packaging to detect unsafe food condition due to the Salmonella presence. However, additional studies should be done to get this film ready to be used in the food market.
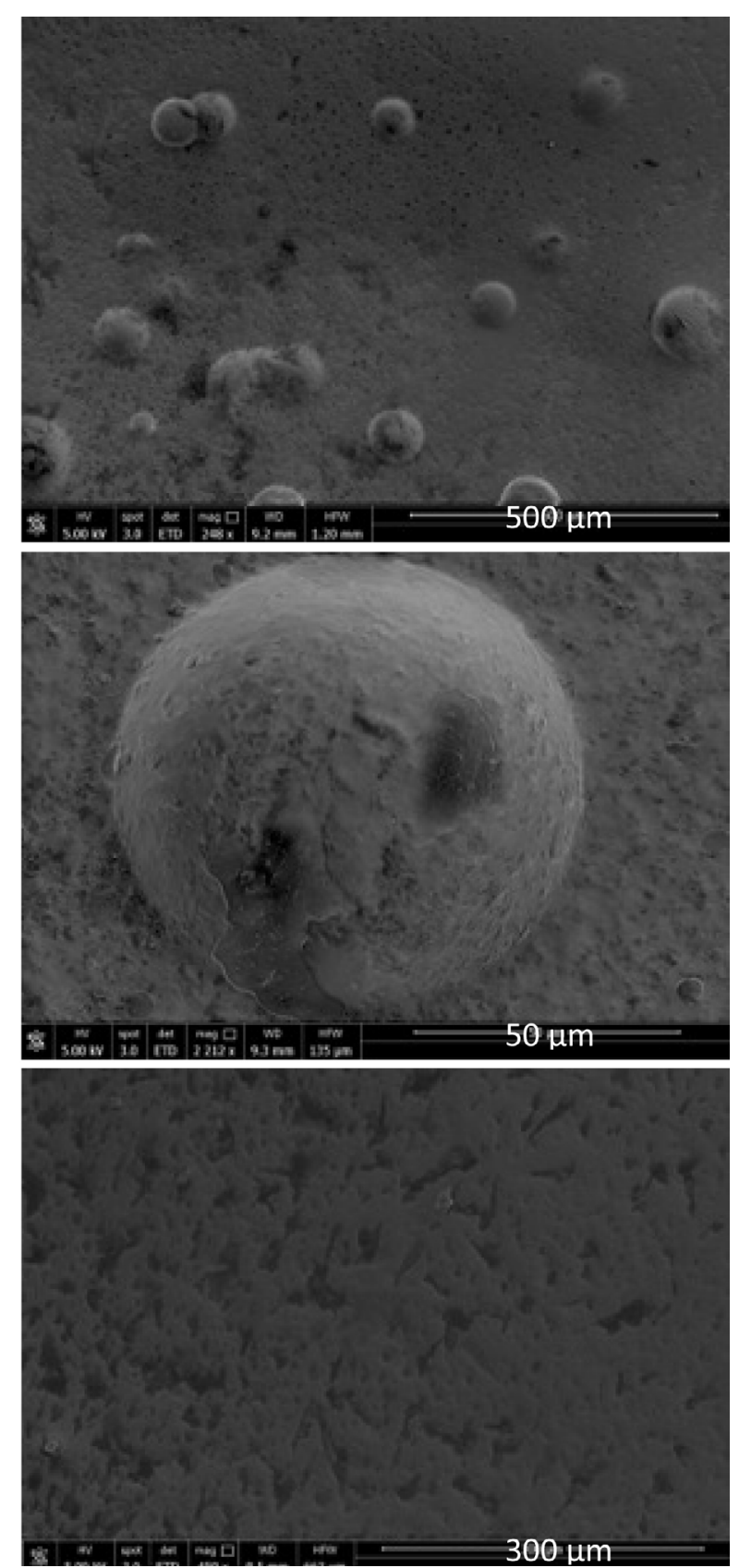

Figure 7: SEM pictures of PDA vesicles incorporated with phage PVPSE1 embedded in methyl cellulose and PDA vesicles without receptor incorporation (PVP-SE1).

\section{Conclusion}

In this study, an advanced packaging was developed using a new recognition element, phage PVP-SE1, which was incorporated in the PDA vesicles embedded in methylcellulose, to detect the Salmonella presence using a colorimetric technique. Primarily, it was investigated PDA vesicles performance incorporated with the PVP-SE1 phage, which is usually utilized as a receptor in biosensor researches. PDA-PVP-SE1 was also capable to discriminate unmarked bacteria from Salmonella strains by coloration change from blue to purple, since in the Salmonella presence color alteration was from blue to red, independently serovars types. When PDA-PVP-SE1 were embedded in methylcellulose (film), the capability to detect Salmonella specifically due to color transition maintained, which was indicated by red color. Moreover, the food borne pathogens indications have occurred due to color change from blue to purple. The PDA-PVP-SE1methylcellulose (film) has needed inferior time ( $24 \mathrm{~h})$ to change color than liquid phase systems. Therefore, this system could be used as advanced packaging, signalizing unsafe conditions for consumers and safeguarding security and beneficial quality of the product at microbiological point of view. Color change was confirmed by both unaided eye and by quantitative methods. Different analyses, such as SEM, have confirmed PDA vesicle embedded in cellulose methyl occurrence uniquely when PVP-SE1 phage was incorporated, promoting stability during film processing and maintaining the specificity to Salmonella. PDA vesicle presence embedded in methylcellulose, have demonstrated a distinguished intelligent packaging potential, representing feasible applications in food market.

\section{Acknowledgements}

The authors thank the CAPES, CNPq, FAPEMIG, and FINEP for the financial support; INL and University of Minho for the knowledge and infrastructure support.

\section{References}

1. dos Santos Pires AC, de Fátima Ferreira Soares N, da Silva LHM, do Silva MDCH, de Almeida MV, et al. 2011. A colorimetric biosensor for the detection of foodborne bacteria. Sens Actuators B Chem 153(1): 17-23. https://doi.org/10.1016/j.snb.2010.09.069

2. Jiang H,Zhao X, Shelton AH,Lee SH, Reynolds JR, et al.2009. Variableband- gap poly (arylene ethynylene) conjugated polyelectrolytes adsorbed on nanocrystalline $\mathrm{TiO}_{2}$ : photocurrent efficiency as a function of the band gap. ACS Appl Mater Interfaces 1(2): 381-387. https://doi. org/10.1021/am800089n

3. Kim J, Swager TM. 2001. Control of conformational and interpolymer effects in conjugated polymers. Nature 411: 1030-1034. https://doi. org $/ 10.1038 / 35082528$

4. Kim J, Levitsky IA, McQuade DT, Swager TM. 2002. Structural control in thin layers of poly (p-phenyleneethynylene)s: photophysical studies of Langmuir and Langmuir-Blodgett films. J Am Chem Soc 124(26): 7710-7718. https://doi.org/10.1021/ja0200600

5. Lebouch N, Garreau S, Bellete M, Durocher G, Leclerc M, et al. 2005. Structural study of the thermochromic transition in poly (2,5-dialkylp-phenyleneethynylene)s. Macromolecules 38(23): 9631-9637. https:// doi.org/10.1021/ma051342y

6. Wang Y, Zappas II AJ, Wilson JN, Kim I, Solntsev KM, et al. 2008. Optical spectroscopy of grafted poly (p-phenyleneethynylene)s in water and water-DMF mixtures. Macromolecules 41(4): 1112-1117. https:// doi.org/10.1021/ma702555

7. Seo SB. 2014. Strategies toward highly sensitive polydiacetylene supramolecules based biosensors. University of Michigan, MI, USA.

8. Silverton EW, Navia MA, Davies DR. 1977. Three-dimensional structure of an intact human immunoglobulin. Proc Natl Acad Sci U S A 74(11): 5140-5144. https://doi.org/10.1073/pnas.74.11.5140

9. de Oliveira TV, Soares Nde F, de Andrade NJ, Silva DJ, Medeiros EA, 
et al. 2015. Application of PCDA/SPH/CHO/Lysine vesicles to detect pathogenic bacteria in chicken. Food Chem 172: 428-432. https://doi. org/10.1016/j.foodchem.2014.09.055

10. Brenner DJ, Fammer JJ. 2015. Enterobacteriaceae. Bergey's manual of systematics of archaea and bacteria. https://doi. org/10.1002/9781118960608.gbm01154

11. Fernandes E, Martins VC, Nóbrega C, Carvalho CM, Cardoso FA, et al. 2014. A bacteriophage detection tool for viability assessment of Salmonella cells. Biosens Bioelectron 52: 239-246. https://doi. org/10.1016/j.bios.2013.08.053

12. Lee J, Pyo M, Lee S, Kim J, Ra M, et al. 2014. Hydrochromic conjugated polymers for human sweat pore mapping. Nature Commun 5: 3736 https://doi.org/10.1038/ncomms4736

13. Kim JM, Lee YB, Chae SK, Ahn DJ. 2006. Patterned color and fluorescent images with polydiacetylene supramolecules embedded in poly(vinyl alcohol) films. Adv Funct Mater 16(16): 2103-2109. https:// doi.org/10.1002/adfm.200600039

14. Kuswandi B, Wicaksono Y, Jayus, Abdullah A, Heng LY, et al. 2011. Smart packaging: sensors for monitoring of food quality and safety. Sens Instrum Food Qual Saf 5(3): 137-146. https://doi.org/10.1007/s11694011-9120-x

15. Schilthuizen SF. 1999. Communication with your packaging: possibilities for intelligent functions and identification methods in packaging. Packaging Technology and Science 12(5): 225-228. https:// doi.org/10.1002/(SICI)1099-1522(199909/10)12:5<225::AIDPTS476>3.0.CO;2-R

16. Scindia Y, Silbert L, Volinsky R, Kolusheva S, Jelinek R. 2007. Colorimetric detection and fingerprinting of bacteria by glasssupported lipid/polydiacetylene films. Langmuir 23(8): 4682-4687. https://doi.org/10.1021/la0636208

17. Sillankorva S, Pleteneva E, Shaburova O, Santos S, Carvalho C, et al. 2010. Salmonella Enteritidis bacteriophage candidates for phage therapy of poultry. J Appl Microbiol 108(4): 1175-1186. https://doi. org/10.1111/j.1365-2672.2009.04549.x

18. Dong W, Luo J, He H, Kim L. 2013. A reinforced composite structure composed of polydiacetylene assemblies deposited on polystyrene microspheres and its application to $\mathrm{H} 5 \mathrm{~N} 1$ virus detection. Int $J$ Nanomedicine 8: 221-232. https://doi.org/10.2147/IJN.S39676

19. de Oliveira TV, Soares N de F, Coimbra JS dos R, Andrade NJ, Moura LG, et al. 2015. Stability and sensitivity of polydiacetylene vesicles to detect Salmonella. Sens Actuators B Chem 221: 653-658. https://doi. org/10.1016/j.snb.2015.06.130

20. Charych DH, Nagy JO, Spevak W, Bednarski MD. 1993. Direct colorimetric detection of a receptor-ligand interaction by a polymerized bilayer assembly. Science 261(5121): 585-588. https://doi.org/10.1126/ science. 8342021

21. Wut J, Zawistowski A, Ehrmann M, Yi T, Schmuck C. 2011. Peptide functionalized Polydiacetylene Liposomes Act as a fluorescent turn-on sensor for bacterial lipopolysaccharide. J Am Chem Soc 133(25): 97209723. https://doi.org/10.1021/ja204013u

22. Davis BW, Burris AJ, Niamnont N, Hare CD, Chen C, et al. 2014. Dual-mode optical sensing of organic vapors and proteins with polydiacetylene (PDA)-embedded electrospun nanofibers. Langmuir 30(31): 9616-9622. https://doi.org/10.1021/la5017388

23. Oliveira TV, Soares NFF, Silva DJ, Andrade NJde, Medeiros EAA, et al. 2013. Development of PDA/Phospholipids/Lysine vesicles to detectpathogenic bacteria. Sens Actuators B Chem 188: 385-392. https:// doi.org/10.1016/j.snb.2013.06.022

24. dos Santos Rodrigues JB, Pinto TS, de Oliveira CP, de Sousa Freitas FI, Vieira Pereira Mdo S, et al. 2014. Lipolytic activity of Staphylococcus aureus from human wounds, animals, foods, and food-contact surfaces in Brazil. J Infect Dev Ctries 8(8): 13-16. https://doi.org/10.3855/ jidc. 3697

25. Kilroy S, Raspoet R, Martel A, Bosseler L, Appia-Ayme C, et al. 2017. Salmonella Enteritidis flagellar mutants have a colonization benefit in the chicken oviduct. Comp Immunol Microbiol Infect Dis 50: 23-28. https://doi.org/10.1016/j.cimid.2016.11.002

26. Meir D, Silbert L, Volinsky R, Kolusheva S, Weiser I, et al. 2008. Colorimetric fluorescent bacterial sensing by agarose-embedded lipid/ polydiacetylene films. J Appl Microbiol 104(3): 787-795. https://doi. org/10.1111/j.1365-2672.2007.03614.x

27. Ma B, Fan Y, Zhang L, Kong X, Li Y, et al. 2003. Direct colorimetric study on the interaction of Escherichia coli with mannose in polydiacetylene Langmuir-Blogett films. Colloids Surf B Biointerfaces 27(2-3): 209-213. https://doi.org/10.1016/S0927-7765(02)00067-X

28. Afshari-Jouybari H, Farahnaky A. 2011. Evaluation of photoshop software potential for food colorimetry. J Food Eng 106(2): 170-175. https://doi.org/10.1016/j.jfoodeng.2011.02.034

29. Pevzner A, Kolushwva S, Orynbayeva Z, Jelinek R. 2008. Giant chromatic lipid/polydiacetylene vesicles for detection and visualization of membrane interactions. Adv Funct Mater 18(2): 242-247. https://doi. org/10.1002/adfm.200700726 